\title{
Finegoldia magna
}

National Cancer Institute

\section{Source}

National Cancer Institute. Finegoldia magna. NCI Thesaurus. Code C86888.

A species of anaerobic, Gram positive, cocci shaped bacterium assigned to the phylum Firmicutes. F. magna cannot ferment most sugars aside from fructose and possesses various aminopeptidase activities. A commensal bacterium, it's most notably involved in human skin and soft tissue infection. 